\title{
Context effects in retrospective judgments of personal experiences
}

\author{
JOHN A. ROBINSON \\ University of Louisville, Louisville, Kentucky 40208
}

\begin{abstract}
Are retrospective judgments regarding the affect associated with personal experiences influenced by organismic and cognitive factors prevailing at the time such events are recalled? This experiment examined whether contrast and assimilation effects analogous to those obtained for social and perceptual judgments could be produced in memory judgments of affect. The contribution of two factors was assessed: current activation level and cognitive context. Memories of personal experiences were elicited by a prompt-word method (cf. Robinson, 1976). Activation level was assessed by a self-report measure (Thayer, 1967). Cognitive contexts biased toward highly affecting experiences or toward moderately affecting experiences were induced with special questionnaires. Nonevaluative features of personal memories (e.g., event age) were not affected by the judgment conditions. Judgments of affect intensity were shifted relative to a neutral baseline condition by the high-intensity cognitive context. The direction of judgmental shift was dependent upon activation level. Confidence rating indicated that subjects were not aware of the biasing effects of the recall conditions.
\end{abstract}

The question examined in this paper is whether cognitive and organismic factors prevailing at the time of recall influence judgments about the affective qualities of remembered experiences. Does one's present state of mind influence retrospective reports (or claims) about previous subjective states? Robinson (1980) has suggested that reports about feelings are subject to context effects and that changes in appraisal from one occasion to the next of the kind reported by Holmes (1970) are viewed more appropriately as context-guided judgments than as evidence of recoding of affect in memory representations.

Context-induced contrast effects have been obtained in studies of the perception of affective qualities of sensory stimuli (Hunt \& Volkmann, 1937) and of facial and/or verbally expressed emotion (Manis, 1967), but the occurrence of context effects in memory reports of affect has not yet been directly investigated. Recent studies of autobiographical memory have reaffirmed the significance of affect in memory retrieval (Robinson, 1980). The method developed in that research can be used to explore judgmental variables in retrospective reports about life experiences.

Ideally, we would wish to have empirical information about subjective appraisals of feeling at the time events occurred as a basis for assessing situational influences on retrospective reports. It is not always feasible to get such information, and for certain problems, it is not essential. For example, prior research demonstrated that a standardized procedure for memory evocation reliably yielded memory reports that, in aggregate, were comparable in descriptive and evaluative characteristics across a variety of retrieval conditions (Robinson, 1980). In the present study, the stability of report characteristics demonstrated by prior research provides a procedural model of a baseline or neutral context condition. By varying the circumstances in which retrospective reports are evaluated, we can determine, relative to a baseline or neutral context, whether situational factors produce reliably different judgments of experienced affect. Retrospective reports of affect may be either enhanced or diminished by contextual variables. Following the model of social judgment such context-induced judgmental shift can be described as either contrast or assimilation effects, depending on the direction of the shift relative to the baseline condition.

What factors prevailing at the time a prior experience is recalled might induce contrast or assimilation effects vis-à-vis memory judgments of the affective qualities of the event? Two intuitively plausible factors are cognitive context and activation level. Cognitive context refers to the aggregate of recent thoughts, memories, and feelings; activation level is the degree of nonspecific arousal. Responses to a self-report inventory provided the basis for comparing the effect of levels of activation on retrospective evaluations. Contrasting cognitive contexts were induced by means of life experiences inventories (LEIs) specially devised for this experiment. Memories of personal experiences were elicited as responses to a series of cue words (cf. Robinson, 1976). With this method, comparisons could be made among the varying conditions regarding nonevaluative features of memories (e.g., retrieval latency, event age), as well as evaluative characteristics (e.g., intensity of effect, pleasantness). If the conditions are equivalent on nonevaluative features but significantly different on evaluative measures, we may conclude that retrospective appraisals of feeling are subject to context effects. 


\section{METHOD}

The experiment was based on a 2 by 3 factorial design: Two levels of activation (high vs. low) and three cognitive contexts (high intensity, low intensity, and neutral). Using a prompted recall procedure (cf. Robinson, 1976), memories of specific personal experiences were elicited from the subjects. The retrieval stage of the experiment was the same for all subjects. Variations of cognitive context were introduced between the retrieval phase and the rating phase of the experiment. Activation level was assessed at the beginning of the experimental session in order to assess the effect of this variable on retrieval as well as on retrospective rating.

\section{Subjects}

Sixty students enrolled in introductory psychology served as subjects to fulfill a course requirement. There were approximately equal numbers of males and females. The subjects ranged in age from 17 to 25 years; the average age was 19 years.

\section{Materials}

A list of 30 prompt words used by Robinson (1980, Experiment 3 ) provided the stimulus materials. The 30 words were arranged into three subsets comparable in their normative properties. Four randomizations of the list were prepared by reordering the various subsets of prompts. Six additional words were selected for use as practice items.

\section{Procedure}

Before the prompted recall task was administered, each subject completed the short form of Thayer's (1967) ActivationDeactivation Adjective Check List (ACL). Subjects were assigned to groups on the basis of total scores on the Deactivation-sleep (DAS) subscale of the ACL. Russell (1979) has recently shown that the DAS scale is the only one of the four Thayer subscales that is uncorrelated with pleasantness/unpleasantness. DAS scores are based on a 4-point weighting of responses to five adjectives. Subjects with scores of 5 to 10 were regarded as evidencing a high activation level; those with scores from 11 to 20 were regarded as evidencing a low activation level. The experimenter scored the ACL immediately and randomly assigned the subject to one of the three context conditions.

After completing the ACL, subjects were given instructions about the recall task. Because the instructions and procedures have been described in detail in previous reports (Robinson, 1976,1980 ), only a brief summary of these details will be given here. For each prompt word, subjects were to respond with the first specific personal experience that came to mind. The words were presented on a memory drum and report latency was timed by the experimenter with an electronic digital stopwatch. Subjects were given $1 \mathrm{~min}$ to respond. If no response was signaled by the end of that interval, the next prompt word was presented. After pressing a telegraph key to indicate recall of an event, subjects wrote a brief summary of the remembered event. No additional descriptive or evaluative information was obtained at this point in the task.

When the list of memory prompts was completed, subjects in the neutral context condition were given two pages of the Identical Pictures Test (French, Ekstrom, \& Price, Note 1) to complete. The 40 form-matching items took approximately $2 \mathrm{~min}$ to finish. Those subjects assigned to the two biasing context conditions were given the appropriate version of LEI. Each inventory consisted of 52 phrases designating a variety of life events, 26 pleasant and 26 unpleasant experiences. The 52 items on the version of LEI used in the high-intensity context condition all designated intensely affecting experiences [e.g., "earned top award in (scouting/athletics)"; "a parent hospitalized"]. The 52 items on the version of the LEI used in the lowintensity context condition designated less affecting experiences [e.g., "go on a family picnic"; "break a (glass/cup/dish)"]. Intensity rather than pleasantness was selected as the dimension of the affect most likely to yield context effects because recent research on autobiographical memory (Robinson, 1980) had shown that it was systematically associated with interesting features of remembering. Both forms of the LEI were pretested on an independent group of 30 subjects to determine whether there was sufficient consensus about the pleasantness and the intensity of feeling of the 104 events. The results indicated that there was $90 \%$ agreement with the experimenter's judgments regarding pleasantness and $80 \%$ agreement with the experimenter's judgments of intensity. The LEI instructions given to subjects in the experiment proper included the following explanation: "A wide variety of events and experiences are listed on the following pages. The inventory is being used to determine how often different kinds of experiences occur as part of normal development in modern society."

When they had finished either the Identical Pictures Test or an LEI, subjects were given instructions for rating the affect associated with each of the life memories elicited by the list of prompt words. They were directed to rate the intensity of feeling at the time the experience occurred and to indicate the level of confidence for each rating. The instructions explicitly requested ratings of original rather than present intensity of feeling and also indicated that intensity rather than pleasantness was the attribute to be judged. A 7-point scale was used, with the extremes labeled "neutral" and "very intense." Half of the subjects in each condition used the scale in the very intense/ neutral scale order, and half used a scale that reversed the order of terms. Confidence judgments were marked on the same form as the intensity rating and entailed a choice of three levels: very confident, confident, and uncertain. Even summaries were given to subjects in the same order in which they had been obtained. This assured that a roughly comparable time period intervened between retrieval and rating for each episode.

Finally, after all reports had been rated for intensity of feeling, subjects were instructed to date each event in terms of a month and year and to indicate whether the experience had been pleasant, neutral, or unpleasant.

\section{RESULTS}

All protocols were first examined to determine whether any noncriterial responses occurred. Reports of repeated or continuous activities (e.g., "I played football in high school") or responses that were simply associations to a prompt word rather than a discrete event (e.g., tobacco: "My father smokes") were omitted from all data analyses. The average number of such reports deleted was 1.45 ; there were no differences among the six groups in this regard. The average number of memory reports retained for analysis ranged from 28.10 in the low-activation/low-context condition to 29.00 in the high-activation/high-context condition. The average across all groups was 28.55 .

Five summary measures were computed for each subject in each condition: (1) median report latency, (2) median event age, (3) mean rating of original intensity of feeling, (4) proportion of reports characterized as "unpleasant," and (5) mean confidence rating. Event age was quantified by converting the calendar dates provided by subjects into a numerical score corresponding to the number of months back in time from the date of participation in the experiment. Confidence level was quantified by assigning a score of 5 to "very confident," 3 to "confident," and 1 to "uncertain." The means and standard deviations for measures of retrieval time and 
age of remembered events are presented in Table 1. Also shown is the average DAS score for each condition. The results of a 2 by 3 (activation level by context) analysis of variance on median latency scores indicated that there were no significant differences as regards retrieval time among the six conditions. As can be seen from Table 1, the time span reflected in the memory reports was extremely variable both within and across conditions. Inspection of the data on event age suggests that more recent memories were evoked from low-activation subjects than from high-activation subjects. However, a 2 by 3 analysis of variance indicated that there were no significant differences in event age associated with either activation level or context. These results lead to the conclusion that the retrieval processes of subjects in the several groups were sufficiently comparable to permit interpretation of the postretrieval effects of context without fear of confounding due to differences in memory samples.

The results of the postretrieval affect ratings are presented in Table 2 for each condition. A 2 by 3 analysis of variance on mean intensity ratings indicated that context was not a significant factor, but that the main effect of activation level was marginally significant

Table 1

Summary of Retrieval Latency and Event Age Information in Each Condition

\begin{tabular}{|c|c|c|c|c|c|c|}
\hline \multirow{3}{*}{$\begin{array}{c}\text { Cognitive } \\
\text { Context }\end{array}$} & \multicolumn{4}{|c|}{ Report Measure } & \multirow{2}{*}{\multicolumn{2}{|c|}{$\begin{array}{l}\text { Deactivation/ } \\
\text { Sleep Score }\end{array}$}} \\
\hline & \multicolumn{2}{|c|}{ Latency* } & \multicolumn{2}{|c|}{ Event Age $†$} & & \\
\hline & Mean & SD & Mean & SD & Mean & SD \\
\hline & \multicolumn{6}{|c|}{ High Activation Level } \\
\hline $\begin{array}{l}\text { Neutral } \\
\text { Low } \\
\text { High }\end{array}$ & $\begin{array}{l}4.29 \\
4.45\end{array}$ & $\begin{array}{l}4.16 \\
3.57 \\
2.57\end{array}$ & $\begin{array}{l}42.85 \\
43.55 \\
17.25\end{array}$ & $\begin{array}{l}35.21 \\
41.62 \\
11.99\end{array}$ & $\begin{array}{l}6.30 \\
6.40 \\
6.90\end{array}$ & $\begin{array}{l}1.25 \\
1.71 \\
1.85\end{array}$ \\
\hline High & \multicolumn{6}{|c|}{ Low Activation Level } \\
\hline $\begin{array}{l}\text { Neutral } \\
\text { Low } \\
\text { High }\end{array}$ & $\begin{array}{l}3.89 \\
5.11 \\
4.70\end{array}$ & $\begin{array}{l}2.14 \\
3.28 \\
2.41\end{array}$ & $\begin{array}{l}22.90 \\
27.60 \\
31.40\end{array}$ & $\begin{array}{l}27.23 \\
35.40 \\
43.10\end{array}$ & $\begin{array}{l}14.10 \\
15.30 \\
14.10\end{array}$ & $\begin{array}{l}2.51 \\
1.70 \\
1.60\end{array}$ \\
\hline
\end{tabular}

*Median latency (in seconds). TMedian event age (in months).

Table 2

Summary of Affect Ratings in Each Condition

\begin{tabular}{|c|c|c|c|c|c|c|}
\hline \multirow{3}{*}{$\begin{array}{c}\text { Cognitive } \\
\text { Context }\end{array}$} & \multicolumn{4}{|c|}{ Report Measure } & & \\
\hline & \multicolumn{2}{|c|}{$\begin{array}{c}\text { Mean } \\
\text { Intensity }\end{array}$} & \multicolumn{2}{|c|}{$\begin{array}{l}\text { Proportion } \\
\text { Unpleasant }\end{array}$} & \multicolumn{2}{|c|}{$\begin{array}{c}\text { Mean } \\
\text { Confidence }\end{array}$} \\
\hline & Mean & SD & Mean & SD & Mean & SD \\
\hline & \multicolumn{6}{|c|}{ High Activation Level } \\
\hline $\begin{array}{l}\text { Neutral } \\
\text { Low } \\
\text { High }\end{array}$ & $\begin{array}{l}4.77 \\
4.66 \\
5.18\end{array}$ & $\begin{array}{l}.45 \\
.75 \\
.45\end{array}$ & $\begin{array}{l}.51 \\
.46 \\
.48\end{array}$ & $\begin{array}{l}.12 \\
.17 \\
.12\end{array}$ & $\begin{array}{l}3.68 \\
4.03 \\
4.03\end{array}$ & $\begin{array}{l}.59 \\
.33 \\
.46\end{array}$ \\
\hline High & \multicolumn{6}{|c|}{ Low Activation Level } \\
\hline $\begin{array}{l}\text { Neutral } \\
\text { Low } \\
\text { High }\end{array}$ & $\begin{array}{l}4.68 \\
4.83 \\
4.23\end{array}$ & $\begin{array}{l}.44 \\
.80 \\
.68\end{array}$ & $\begin{array}{l}.49 \\
.44 \\
.51\end{array}$ & $\begin{array}{l}.06 \\
.11 \\
.11\end{array}$ & $\begin{array}{l}3.97 \\
3.92 \\
3.62\end{array}$ & $\begin{array}{l}.50 \\
.51 \\
.78\end{array}$ \\
\hline
\end{tabular}

$[\mathrm{F}(1,54)=3.35, \mathrm{MSe}=.37, \mathrm{p}<.10]$. However, the interaction of context and activation level was statistically significant $[\mathrm{F}(2,54)=4.59, \mathrm{MSe}=.37, \mathrm{p}<.02]$. As can be judged from Table 2, this interaction was due solely to the high-context conditions. Supplementary tests demonstrated that for both activation levels, highcontext ratings were significantly different from neutral context ratings [for high activation, $t(18)=2.10$, $\mathrm{p}<.03$; for low activation, $\mathrm{t}(18)=-1.73, \mathrm{p}<.05$; both one-tailed tests]. At neither activation level were low-context ratings significantly different from the respective neutral context ratings.

Analysis of the confidence judgments for intensity ratings indicated that there were no significant differences in average confidence among the six conditions. Inspection of the data in Table 2 suggested that while the two high-context groups were not significantly different from their respective neutral control groups, they might be significantly different from each other. Since these were the only two groups that demonstrated significant context effects vis-à-vis rated intensity, it would be particularly interesting to find that confidence judgments were influenced in a comparable way. However, the difference in mean confidence was only marginally significant $[\mathrm{t}(18)=-1.43, \mathrm{p}<.10$; two-tailed test $]$. Thus, the biasing effect of the high-intensity context did not substantially influence subjective appraisal of the validity of intensity ratings. Finally, no differences were obtained in the proportion of memory reports characterized as "unpleasant." Thus context influenced the degree (i.e., intensity) of pleasantness or unpleasantness attributed to events, but it apparently did not alter the categorization of events (i.e., from pleasant to unpleasant or vice versa).

In order to determine whether differences in responses to the LEI might be responsible for any of the results described above, the number of items checked was tabulated for each subject in each of the four LEI groups. The mean number of items checked was as follows: for high-activation groups, 28.50 and 46 for high and low context, respectively; for low-activation groups, 26.10 and 44 for high and low context, respectively. The results of a 2 by 2 analysis of variance indicated that significantly more items were checked on the low-context LEI than on the high-context LEI $[F(1,36)=75.63, p<.001]$. There were no differences, however, as a function of activation level, nor was the interaction of context and activation statistically significant.

\section{DISCUSSION}

This study was conducted to determine whether retrospective appraisal of the intensity of affect engendered by previous experiences could be systematically influenced by factors prevailing at the time that memories of those experiences were evoked. Two factors, cognitive context and activation level, were examined. The principal result of the study was that, relative to a neutral context, context-induced contrast and assimilation effects vis-d-vis retrospective ratings of affect intensity were 
obtained. However, these effects were obtained only when the cognitive context was biased toward highly intense reactions. A cognitive context biased toward experiences that would elicit affect of moderate to low intensity did not significantly influence retrospective ratings. Furthermore, the direction of the context effect was dependent upon level of activation: If activation level was high, intensity ratings were significantly increased; if activation level was low, ratings were significantly reduced relative to the neutral context at a comparable activation level. Thus, neither activation level per se nor a low-intensity cognitive context significantly influenced affect reports. This implies that mere variation in activation level (whether cyclically or in response to stimulation) is not a sufficient condition for influencing retrospective judgments of feeling. Rather, the associated stream of thoughts, memories, and other associations must have a modal valence above the norm in affect intensity. This qualitative feature of consciousness may then act in conjunction with activation level to bias retrospective reports.

The fact that retrospective judgments of feeling were susceptible to context effects indicates that remembered affect may be more properly viewed as the product of judgment processes rather than simply as an unmediated report of memory data. In this respect, memory resembles perception: That is, the subjective value assigned to a focal event is the result of interactions among several concurrent sources of stimulation or information. Note that this fluctuation in the subjective appraisal of a past event cannot be explained by simply declaring that the person's feelings have changed. That view, similar to the one proposed by Holmes (1970), makes no allowances for situational factors in retrospective appraisals.

The results of this research provide another demonstration of the plasticity of memory information. But there are important differences between cases such as the one reported here of contextual influences on judgments and those in which contextguided reconstructions occur. The latter is well illustrated by Loftus' (1979) research on eyewitness testimony. There is little doubt that distortion and confabulation occur in certain types of remembering. Nevertheless, people are more easily misled about some things than about others. In particular, people are more likely to be misled about what they may have seen or heard than about how they felt. Specifically, while it may be possible to induce a person to believe that a thief wore a purple shirt instead of a green shirt, it does not seem likely that we could induce a person to believe he or she felt curiosity rather than fear. We can, however, if present results are to be credited, induce an individual to report more or less fear under appropriate circumstances. Furthermore, it seems unlikely that a person could be repeatedly induced to change his mind about stimulus characteristics of witnessed events. Viewing remembered affect in terms of a model of social judgment leads quite naturally, however, to expectations of moderate situational variability in affect reports.

The ways in which evaluative self-perceptions are influenced by the circumstances that elicit those evaluations is a major theme of contemporary psychology. Research on personal memories and influences on retrospective appraisal of life events can help to elaborate that general concern and provide information relevant to a psychology of personal history or autobiography.

\section{REFERENCE NOTE}

1. French, J. W., Ekstrom, R. B., \& Price, L. A. Kit of reference tests for cognitive factors. Princeton, N.J: Educational Testing Service, 1963.

\section{REFERENCES}

Holmes, D. S. Differential change in affective intensity and the forgetting of unpleasant personal experiences. Journal of Personality and Social Psychology, 1970, 15, 234-239.

Hunt, W. A., \& Volkmann, J. The anchoring of an affective scale. American Journal of Psychology, 1937, 49, 88-92.

Loftus, E. F. The malleability of human memory. American Scientist, 1979, 67, 312-320.

Manis, M. Context effects in communication. Journal of Personality and Social Psychology, 1967, 5, 326-334.

RoBinson, J. A. Sampling autobiographical memory. Cognitive Psychology, 1976, 8, 578-595.

Robinson, J. A. Affect and retrieval of personal memories. Motivation and Emotion, 1980, 4, 149-174.

Russell, J. A. Affective space is bipolar. Journal of Personality and Social Psychology, 1979, 37, 345-356.

ThaYER, R. E. Measurement of activation through self-report. Psychological Reports, 1967, 20, 663-678.

(Received for publication February 9, 1981.) 